Jan Dizo - Miroslav Blatnicky - Jozef Harusinec - Alfred Pavlik - Lukas Smetanka*

\title{
STRENGTH ANALISIS OF A FREIGHT BOGIE FRAME UNDER THE DEFINED LOAD CASES
}

This work presents results of strength analyses of a modified freight wagon bogie frame. It consists of two main parts. The first part is addressed to introduction of the structure of a freight wagon bogie frame. It is a modified frame structure, which reflects current requirements of modern railway transport means. The conditions for rail vehicles approval and the main load cases, which every bogie frame must meet for commissioning, are described. The next part deals with computer modelling and analyses of this bogie frame. Strength analyses were performed using the FE method and they were focused on the assessment of stresses in the frame structure. Loads definition and the method of calculation were based on valid norms and standards.

Keywords: freight wagon bogie frame, modified structure, strength analysis, finite element method

\section{Introduction}

The transport of goods by railways represents an important element of a transport service. It is the environmentally friendly kind of goods transport, which is mainly obvious in international and intermodal transport. Therefore, the railway transport is nowadays an inseparable part of the transport system.

The railway transport allows an efficient way to move large quantities of goods over longer distances [1], [2], [3]. Nowadays, the design of rail vehicles has to satisfy conflicting requirements. On one hand it is the rail vehicles weight reducing and on the other hand all the railway transport means must meet the strict safety criteria, standards and norms. Every new designed railway vehicles and also construction units, such as bogies must meet before commissioning satisfy the terms set out in codes [4], [5].

\section{Modified structure of a freight wagon bogie}

By reason that mainly in the region of the Central Europe (Slovak Republic, Czech Republic, Poland, Hungary, Baltic countries, etc.) the freight railway transport makes use of the same railway tracks as passenger railway transport, the question about the stronger depreciation of this infrastructure arises [6], [7], [8]. These negative outcomes strongly relate among other things with the much higher axle load of freight wagons and with different design of freight wagons bogies [9], [10].

The Y25 bogie is the most commonly used bogie for freight wagons. In comparison to bogies for passenger wagons, it features the relatively stiff structure. On one hand there are solutions allowing steering wheelsets in curves by releasing the wheelsets in guidance, but on the other hand such a design meets problems when a freight wagon passes straight sections of tracks [11], [12], [13], [14]. These facts have led engineers to the modification of the original Y25 bogie design. Basis of the modification of the bogie consists of removing the buffer beams and in partial modifications of some other parts (increasing thicknesses of same sheets in structure) [15], [16]. Such a modified bogie cannot any longer use standard block brake acting on both side of a wheel, but it is equipped with the integrated block brake unit acting on one side of a wheel or with a disc brake [17]. The decreasing of the bogie mass is another important advantage of such a technical solution. When one compares the original Y25 bogie, equipped with the standard block brake, to the modified Y25 bogie design, equipped with the block brake unit, it can save up to $250 \mathrm{~kg}$ [15] and as standard freight wagons use two bogies, the mass of wagons is not longer negligible. Both bogie designs are shown in Figure 1.

From the operation point of view, reducing of the wagon unloaded mass means increasing the wagon capacity weight, lower operating costs when a wagon is transported in an unloaded state by saving energy consumption [18], and from the production point of view, one can save in material costs and partly reduce the needed production time.

The bogie frame is the main carrying part of the bogie. Therefore it is not possible to perform such an essential modification of the frame without adequate analyses. They come out and rely on strict requirements embedded in relevant standards and regulations. In the European standard the considered analysed bogie is classified in the category B-V: bogies freight rolling stock with single-stage suspensions [4].

\section{Prescribed loads for freight wagon bogies}

Freight bogies are loaded in real operational conditions by a wide spectrum of loads, which depends on actual level of loading, quality of a track expressed by variations from its geometrically

\footnotetext{
* ${ }^{1}$ Jan Dizo, ${ }^{1}$ Miroslav Blatnicky, ${ }^{1}$ Jozef Harusinec, ${ }^{1}$ Alfred Pavlik, ${ }^{2}$ Lukas Smetanka

${ }^{1}$ Department of Transport and Handling Machines, Faculty of Mechanical Engineering, University of Zilina, Slovakia

${ }^{2}$ Department of Design and Mechanical Elements, Faculty of Mechanical Engineering, University of Zilina, Slovakia

E-mail: jan.dizo@fstroj.uniza.sk
} 

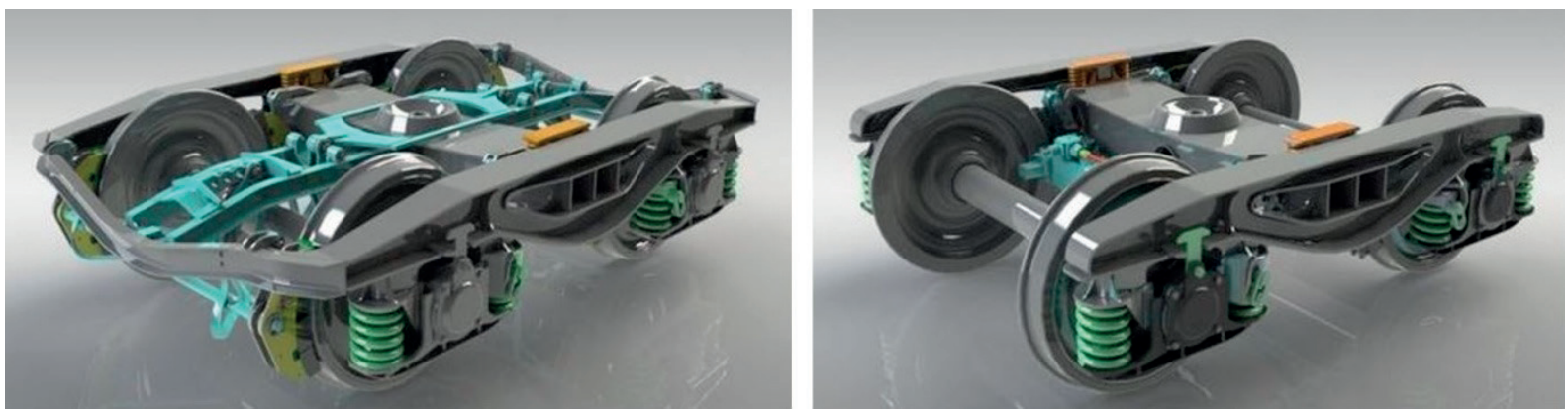

Figure 1 The original Y25 bogie (left) and the modified Y25 bogie (right)

ideal position load or an eventual buckling of the track in the given track section and various others factors. Therefore, for the load of bogie frames the replacement load spectrum was determined according to which new developed bogies are tested [19]. In this work the modified bogie frame was tested using virtual models.

Generally, various load cases of bogies frames can be divided into external and internal. The external load of bogies represents the load relevant to the bogie running on the track, when it has to carry gravitational forces, as well as dynamic forces acting in the vertical and lateral directions. The internal load is caused by the presence and operation of the bogie equipment, such as the brake system, system of suspension with dampers, anti-roll bars system, traction motors and also by masses attached to the bogie frame (inertia effects) etc. [4], [19].

\subsection{Combinations of individual loads}

In reality, loads described above do not occur individually, but they act concurrently in various combinations and in various intensities. For needs of the strength and dynamic design of a bogie frame, the European standards submit several selected load combinations. They are compiled in such a manner, that the designed bogie frame will withstand the possible combined operational loads. In the European standard two combinations of loads are defined, the static load combination and the dynamic load combination. Based on the static load combination and the removal of the static load, the permanent deformations must not occur in the frame structure. In exceptional cases and based on agreement with the vehicle operator, the permanent deformations are compared to the permissible values [4], [19].

Bogie structures are loaded by the very high number of the varying dynamic loads. Effects of such a load are concentrated in critical locations of the analysed bogie frame (e.g. points of action forces, geometry changes, welded joints etc.). The objective of the fatigue tests is verification, if a bogie frame has sufficient fatigue strength, i.e. if a cyclic operational load does not result in initiation of fatigue cracks or fractures. Fatigue stresses are possible to be determined by the two methods, i.e. the fatigue resistance, if the fatigue lifetime is known (stress value, in which under load by determined number of cycles the fatigue damage not occur) and the cumulative damage, if the stress is constantly under the fatigue lifetime level for all the determined load combinations [4], [19].

In this work, only the static load combinations are considered.

\section{Stress analyses of a modified bogie frame}

Ride properties of rail vehicles significantly influence their dynamic behaviour [20]. One can theoretically predict the movement of the wheelset on a track by means of the wheelset and track geometrical characteristics analysis. Geometrical characteristics define the rail/wheel profiles contact couple geometrical relationship. The shape of the contact couple crucially influences the size of the contact patch and contact stress between the wheel and rail value. This creates loading and excitation forces acting inside the vehicle and track systems [21], [22], [23]. The analysis of the mechanical systems dynamics may be conducted using various methods [24].

\subsection{Determination of the loads}

Formulations for determination of the loads are prescribed in the European standard [4]. For these calculations the freight wagon bogie parameters were as follows: the total weight of the bogie was $m=4.25 \mathrm{t}$, wheelbase $b=1.8 \mathrm{~m}$ and the total weight of the wagon $M_{W}=90 \mathrm{t}$, (Figure 2).

The bogie is loaded in the vertical direction by the force:

$F_{Z}=\left(\frac{M_{W}}{2}-m\right) \cdot g$

where $g$ represents the gravitational acceleration of $9.81 \mathrm{~m} \cdot \mathrm{s}^{-2}$. For the vertical direction the value of the exceptional load is given by following formulas:

- if vertical forces act only in the centre pivot:

$F_{Z P_{\max }}=2 \cdot F_{Z}$

- if vertical forces act in the centre pivot and on one side-bearer:

$F_{Z 1 \max }\left(\right.$ or $\left.F_{Z 2 \max }\right)=1.5 \cdot F_{Z} \cdot \alpha$

$F_{Z P}=1.5 \cdot F_{Z}(1-\alpha)$

where $F_{Z}$ is the total vertical load on a bogie, $F_{Z P}$ is the vertical force acting in the centre pivot, $F_{Z 1}$ and $F_{Z 2}$ are vertical forces act on side-bearers, $\alpha$ is coefficient for the body swinging. In this case, the value $\alpha=0.3$ was considered.

For the lateral force of the exceptional load, acting on every wheelset, the following formulation is applied: 


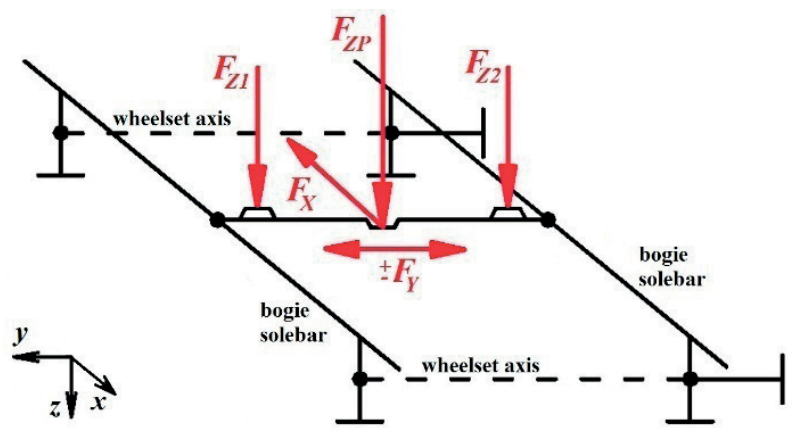

Figure 2 Distribution of loads on a frame

Table 1 Values of the calculated loads

\begin{tabular}{ccc}
\hline Load & Value $[\mathrm{kN}]$ & Formula \\
\hline $\mathrm{F}_{\mathrm{Z}}$ & 399.760 & $(1)$ \\
$\mathrm{F}_{\mathrm{ZP \operatorname {max }}}$ & 799.520 & $(2)$ \\
$\mathrm{F}_{\mathrm{Z} 1 \max }$ & 179.892 & $(3)$ \\
$\mathrm{F}_{\mathrm{ZP}}$ & 419.750 & $(4)$ \\
$\mathrm{F}_{\mathrm{Y} \max }$ & 100.074 & $(5)$ \\
$\mathrm{F}_{\mathrm{X} \max }$ & 44.145 & $(6)$ \\
\hline
\end{tabular}

$F_{Y 1 \max }=F_{Y 2 \max }=\frac{F_{Y \max }}{2}=10^{4}+\frac{F_{Z}+m \cdot g}{6}$

The longitudinal force straining bogie frame is given by:

$F_{X 1 \max }=0.1\left(F_{Z}+m \cdot g\right)$

The load involved in the case of the wagon impact can be substituted by the static longitudinal forces acting in places where the equipment is connected to the bogie. Its value is determined from the mass of individual elements and maximum acceleration acting on them during wagon impact.

\subsection{Simulation calculations and results}

The Ansys software was used for the strength analyses. It allows engineers to create computer models of structures, machine components or whole systems, to apply operating load and other design criteria and to study physical responses [25], [26], [27], such as stress levels, pressure, deformations, etc.

The bogie frame is generally made of the combination S235 and S355 steels, which minimal yield strength is of 340-440 $\mathrm{MPa}$ and 520-630 MPa, respectively. The S355 steel is used for the centre pivot and axle guides. The material is defined as homogenous, isotropic, linear and elastic with the Young's modulus of elasticity $E=2 \cdot 1 \cdot 10^{11} \mathrm{~Pa}$ and Poisson's ratio $\mu=0.3$.

Next are presented results from computer analyses of the modified bogie frame, which was subjected to four load cases corresponding to the exceptional loads described in section 4.1. Table 1 contains calculated data, which are needed to apply as loads on the bogie. The third column indicates which formula from section 4.1 was used for calculation.

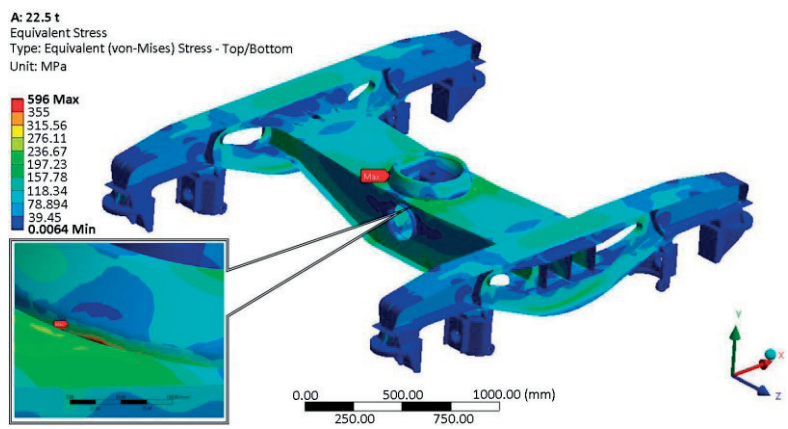

Figure 3 Results of the strength analysis for the $1^{\text {st }}$ load case

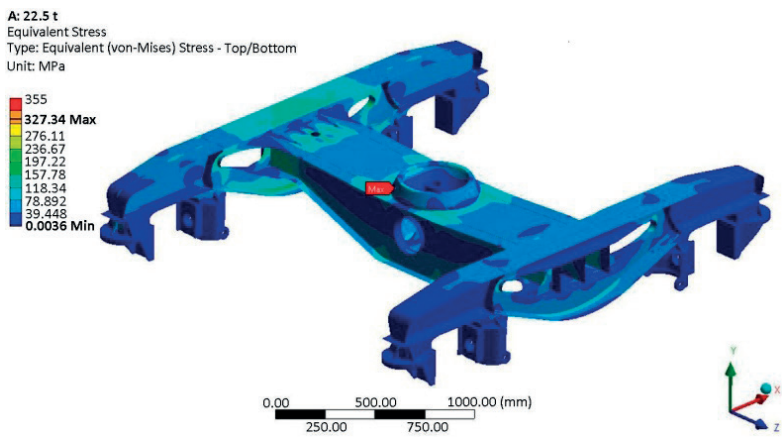

Figure 4 Results of the strength analysis for the $2^{\text {nd }}$ load case

The structure of a bogie frame is acceptable, when it withstands required loads without deflecting to an extent that would impair functionality under the application of the loads or without suffering permanent deformation after removal of the loads [19]. It practically means that for all the load cases, stresses in the whole structure have to be under the yield strength of used material.

Figure 3, Figure 4, Figure 5 and Figure 6 show results from strength analyses of the modified freight wagon bogie frame under prescribed four load cases. Stresses were evaluated according to the HMH hypothesis.

Consider now Figure 3. For the first load case the highest value of the exceptional load $\left(F_{Z P \max }=799.520 \mathrm{kN}\right)$ acts only in the centre pivot. Under this load the highest values of the stresses arise in the middle part of the frame. The maximum calculated stress is $596 \mathrm{MPa}$. It is located in the area of the centre pivot and the cross girder connection. This value is else over the yield strength of the material, but it occurs only locally. One has to consider important facts related to the numerical properties of the FE mesh, so this value can be neglected. Other values are safely below the yield strength. Therefore, the structure complies with given limits for the first load case.

In the second exceptional load case (Figure 4) the frame was loaded by forces acting in the centre pivot and on one side-bearer $\left(F_{Z P}=419.750 \mathrm{kN}\right.$ and $\left.F_{Z I \max }=179.892 \mathrm{kN}\right)$. Such the load model simulates a wagon body swinging. From results (Figure 4) one can see, that the maximum stress is in the loaded side-bearer area and it reaches value of $327.34 \mathrm{MPa}$. In the structure there are no stresses, which could be dangerous for the operation under these analysed load conditions. 


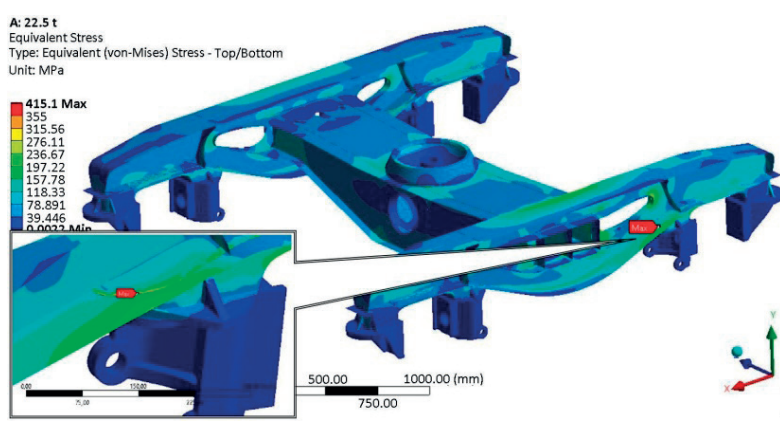

Figure 5 Results of the strength analysis for the $3^{\text {rd }}$ load case

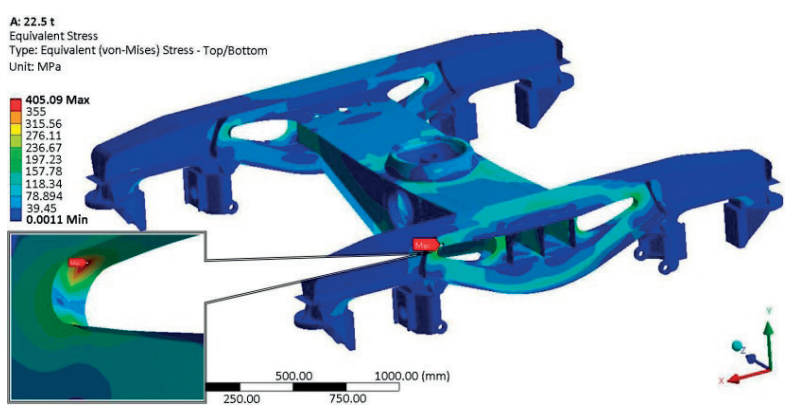

Figure 6 Results of the strength analysis for the $4^{\text {th }}$ load case

\section{Conclusion}

The three-dimensional model of a modified freight wagon bogie frame was created. Since this is a relatively new design of a freight wagon bogie, the objective was to find out if this new frame structure is able to meet strict criteria for all the new designed rail vehicles and their components, mainly the bogies. From the whole scale of load cases, four cases included as exceptional loads, were chosen. The numerical analyses of the bogie frame structure were performed and based on results it was found out that the structure meets requirements prescribed in the standard. For making the clear conclusions it would be necessary to compare results from numerical calculations and measurements to each other. This is the intention for further research in this area. the lateral force, the longitudinal force acts in the centre pivot $\left(F_{X I \max }=44.145 \mathrm{kN}\right)$. This force simulates the dynamic effects caused by traction and braking forces, etc. The maximum stress value (Figure 6) is slightly smaller in comparison to the third load case and it is of 405.1 MPa. It is calculated in the bogie solebar, specifically in the area of the longitudinal girder flange with the upper sheet. This local concentrator is formed due to the reasons described above. The frame structure is able to withstand the fourth load case, as well.

The future research will be focused on investigation of mechanical properties and dynamic behaviour of the entire modified bogie. A mechanical system of the modified bogie in a multibody software will be created and this just analysed FE model will serve as an important input for setting up a multibody system with a flexible body [28], [29] in order to study its dynamic properties and to compare to the original bogie for the detection of possible problems in terms of long-term operation.

\section{Acknowledgement}

This work was supported by the Slovak Research and Development Agency of the Ministry of Education, Science, Research and Sport of the Slovak Republic within the project No. VEGA 1/5058/18 "Research of the interaction of a braked railway wheelset and track in simulated operational conditions of a vehicle running in a track on the test bench".

The work was also supported by the Cultural and Educational Grant Agency of the Ministry of Education of the Slovak Republic within the project No. KEGA 077ZU-4/2017- "Modernization of the Vehicles and engines study program”.

\section{References}

1. MASEK, J., KENDRA, M., MILINKOVIC, S., VESKOVIC, S., BARTA, D.: Proposal and Application of Methodology of Revitalisation of Regional Railway Track in Slovakia and Serbia. Part 1: Theoretical Approach and Proposal of Methodology for Revitalisation of Regional Railways. Transport Problems, 10, 85-95, 2015. https://doi/10.21307/tp-2015-064

2. $\quad$ DVORAK, Z., LEITNER, B., NOVAK, L.: Software Support for Railway Traffic Simulation under Restricted Conditions of the Rail Section. Procedia Engineering, 134, 245-255, 2016. https://doi.org/10.1016/j.proeng.2016.01.066

3. LENDEL, V., PANCIKOVA, L., FALAT, L., MARCEK, D.: Intelligent Modelling with Alternative Approach: Application of Advanced Artificial Intelligence into Traffic Management. Communications - Scientific Letters of the University of Zilina, 19(4), 36-42, 2017.

4. EN 13749, Railway Applications - Wheelsets and Bogies - Method of Specifying the Structural Requirements of Bogie Frames. European Committee for Standardization, Brussels, 2011.

5. UIC 566, Loading of Coaches Bodies and their Components. 1994. 
6. KOSTRZEWSKI, M., CHUDZIKIEWICZ, A.: Rail-Track Quality Indicator towards Rail Driving Dynamics. Proceedings of the $14^{\text {th }}$ Mini Conference on Vehicle System Dynamics, Identification and Anomalies (VSDIA 2014), Hungary, 211-218, 2014.

7. LUNYS, O., DAILYDKA, S., STEISUNAS, S., BUREIKA, G.: Analysis of Freight Wagon Wheel Failure Detection in Lithuanian Railways. Procedia Engineering, 134, 64-71, 2016. https://doi.org/10.1016/j.proeng.2016.01.040

8. HAUSER, V., NOZHENKO, O., KRAVCHENKO, K., LOULOVA, M., GERLICI, J., LACK, T. : Impact of Three Axle Boxes Bogie to the Tram Behavior when Passing Curved Track. Procedia Engineering, 192, 295-300, 2017. https://doi.org/10.1016/j. proeng.2017.06.051

9. CHUDZIKIEWICZ, A., MELNIK, R.: Statistical Analysis of Vibration for the Rail Vehicle Suspension Monitoring System. Proceedings of the $13^{\text {th }}$ Mini Conference on Vehicle System Dynamics, Identification and Anomalies (VSDIA 2012), Hungary, 149-155, 2012.

10. STEISUNAS, S., BUREIKA, G.: Study of Freight Wagon Running Dynamic Stability Taking into Account the Track Stiffness Variation. Transport Problems, 9(4), 131-143, 2014.

11. LACK, T., GERLICI, J., MANUROVA, M.: Freight Car Bogie Properties Analysis by Means of Simulation Computations. Manufacturing Technology, 16(4), 733-739, 2016.

12. SOUKUP, J., SKOCILAS, J., SKOCILASOVA, B.: Assessment of Railway Wagon Suspension Characteristics. Mechanical Systems and Signal Processing, 89, 67-77, 2017. https://doi.org/10.1016/j.ymssp.2016.08.022

13. KLIMENDA, F., SVOBODA, M., RYCHLIKOVA, L., PETRENKO, A.: Investigation of Vertical Vibration of a Vehicle Model Driving Through a Horizontal Curve. Manufacturing Technology, 15(2), 143-148, 2015.

14. MANUROVA, M., SUCHANEK, A.: Determination of Stiffness of Triple Spring Built in a Bogie of a Rail Vehicle. Manufacturing Technology, 16(2), 390-396, 2016.

15. STASTNIAK, P., MORAVCIK, M.: Freight Bogie Prototype Properties Analysis by Means of Simulation Computations. Manufacturing Technology, 17(3), 381-388, 2017.

16. GERLICI, J., GORBUNOV, M., NOZHENKO, O., PISTEK, V., KARA, S., LACK, K., KRAVCHENKO, K.: About Creation of Bogie of the Freight Car. Communications - Scientific Letters of the University of Zilina, 19(2A), 29-35, 2017.

17. GERLICI, J., GORBUNOV, M., KRAVCHENKO, K., PROSVIROVA, O., LACK, T.: The Innovative Design of Rolling Stock Brake Elements. Communications - Scientific Letters of the University of Zilina, 19(2A), 23-28, 2017.

18. FALENDYSH, A., VOLODARETS, M., HATCHENKO, V., VYKHOPEN, I.: Software Analysis for Modeling the Parameters of Shunting Locomotives Chassis. MATEC Web of Conferences, 116, 03003, 2017.

https://doi.org/10.1051/matecconf/201711603003

19. KALINCAK, D., JANICEK, F., KORECZ, K., LANG, A.: Rail Vehicles. Solved Tasks (In Slovak). University of Zilina, 2004.

20. LACK, T., GERLICI, J.: Railway Wheel and Rail Roughness Analysis, Communications - Scientific Letters of the University of Zilina, 11(2), 41-48, 2009.

21. LACK, T., GERLICI, J.: Wheel/Rail Tangential Contact Stress Evaluation by Means of Modified Strip Method. Communications - Scientific Letters of the University of Zilina, 16(3A), 33-39, 2014.

22. SAPIETOVA, A., SAGA, M., STANCEKOVA, D., SAPIETA, M.: Contribution to Numerical Study of Vehicle Vertical Stochastic Vibration. MATEC Web of Conferences, 157, 03015, 2018. https://doi.org/10.1051/matecconf/201815703015

23. SAGA, M., VASKO, M., KOPAS, P., JAKUBOVICOVA, L.: Numerical Algorithm for Beam Residual Stress Identification. Communications - Scientific Letters of the University of Zilina, 16(3A), 13-18, 2014.

24. KULHAVY, P., KOVALOVA, N., VOSAHLO, J.: Methods of Creating a Numerical Model of a Real Seam Based on Experimental Data. Proceedings of the 53 $3^{\text {rd }}$ International Conference on Experimental Stress Analysis (EAN 2015), Czech Republic, 195-202, 2015.

25. BREZANI, M., BARAN, P., LABUDA, R.: Proposal of the Combined Exhaust Gas Heat Exchanger and the Muffler. Diagnostyka, 16(3), 73-78, 2015.

26. VATUliA, G., FALENDYSH, A., OREL, Y., PAVLIUCHENKOV, M.: Structural Improvements in a Tank Wagon with Modern Software Packages. Procedia Engineering, 187, 301-307, 2017. https://doi.org/10.1016/j.proeng.2017.04.379

27. DROPPA, P., HALGAS, P.: Analysis of Hull Protection against Improvised Explosive Devices. Proceedings of the $18^{\text {th }}$ International Conference on Transport Means (Transport Means 2014), Lithuania, 153-156, 2014.

28. DIZO, J., BLATNICKY, M., SKOCILASOVA, B.: Computational Modelling of the Rail Vehicle Multibody System Including Flexible Bodies. Communications - Scientific Letters of the University of Zilina, 17(3), 31-36, 2015.

29. HAUSER, V., NOZHENKO, O., KRAVCHENKO, K., LOULOVA, M., GERLICI, J., LACK., T.: Proposal of a Steering Mechanism for Tram Bogie with Three Axle Boxes. Procedia Engineering, 192, 289-294, 2017. https://doi.org/10.1016/j.proeng.2017.06.050 